\title{
Stable films of zinc-hexacyanoferrate: electrochemistry and ion insertion capabilities
}

\author{
Rosalinda Sciacca $^{1} \cdot$ Silvia Zamponi ${ }^{2} \cdot$ Mario Berrettoni $^{2} \cdot$ Marco Giorgetti $^{3} \mathbb{C}$
}

Received: 29 March 2021 / Revised: 24 June 2021 / Accepted: 5 July 2021 / Published online: 17 July 2021

(c) The Author(s) 2021

\begin{abstract}
A stable film of zinc hexacyanoferrate is deposited on a GC (glassy carbon) substrate following a specific electrochemical protocol. The electrode maintains its characteristic even after dry and wet processes. SEM characterization confirms the cubic morphology of the materials and the IR suggests the presence of the $\mathrm{Fe}^{\mathrm{II}}-\mathrm{C}-\mathrm{N}-\mathrm{Zn}^{\mathrm{II}}$ structural unit. The electrochemical characterization indicates a very good stability of the film, thus opening application in ion exchange system. The focus is on monovalent, divalent, and trivalent ions. These results, the zinc low toxicity, and cost make zinc hexacyanoferrate films a promising candidate for many electrochemical applications.
\end{abstract}

Keywords Zinc hexacyanoferrate $\cdot$ Films $\cdot$ Ionic exchanger $\cdot$ Cyclic voltammetry

\section{Introduction}

In situ generation of thin film materials on a conductive substrate is a useful technique for the preparation of electrodes and electrochemical devices for many technological applications. For instance these methods allow steady film fabrication for ion sensors or ion sieve testing [1-3]. The advantage of the electrodeposition consists of the in situ functionalization of the electrode surface. This allows to tailor the thin film by controlling some experimental variables such as the applied potential, the precursor concentration, and the supporting electrolytes $[4,5]$. The electrode modification could be achieved also by adsorption or via mechanical attachment. Metal hexacyanoferrates (MHCFs) or Prussian Blue analogues (PBAs) are inorganic compounds which were

This paper is dedicated to the memory of our mentor and dear friend Roberto Marassi.

Marco Giorgetti

marco.giorgetti@unibo.it

1 Department of Industrial Chemistry "Toso Montanari”, University of Bologna, UOS Campus Di Rimini, via dei Mille 39, 47921 Rimini, Italy

2 School of Science and Technology, Chemistry Division, University of Camerino, Camerino, Italy

3 Department of Industrial Chemistry "Toso Montanari, University of Bologna," Viale del Risorgimento 4, 40138 Bologna, Italy successfully electrodeposited [6-8]. MHCF thin films fabricated by electrodeposition were used for several applications such as electrocatalysis, energy storage, and above all for ion-sensing detection and exchange capability [9-12]. Their open structures, also called zeolitic-like, allow to intercalate and store alkali cations upon electrical charging, ensuring the electroneutrality of the compounds. So, they are the perfect candidates for the ion separation controlled by electrochemically switched ion exchange systems, which was reported for the first time by Lilga et al. [13]. The method explained the selective and reversible removal of cesium using an electrode modified by Prussian blue analogue. Briefly, the potential was modulated and switched in polarity, forcing the oxidation/reduction of the thin film, which in turn caused the release or uptake of the alkali metal cation, as described by Eq. (1).

$\mathrm{M}\left[\mathrm{Fe}^{\mathrm{III}}(\mathrm{CN})_{6}\right]_{\mathrm{x}}+\mathrm{yA}^{\mathrm{n}+}+\mathrm{ye}^{-} \leftrightarrows \mathrm{A}_{\mathrm{y}} \mathrm{M}\left[\mathrm{Fe}^{\mathrm{II}}(\mathrm{CN})_{6}\right]_{\mathrm{x}}$

Later on, other studies were carried out on the insertion/ de-insertion involving monovalent divalent, and trivalent cations $[14,15]$, which, generally, influence the electrochemical behavior of MHCFs [14, 16, 17]. In particular, their capability as sieves for pollutants like cesium, or for mixed aqueous electrolyte batteries, was widely reported [18-21].

Cations are host in a given lattice site in MHCFs during the reduction reaction, while released during the oxidation step. The relative reduction and oxidation potential are 
closely related to both the hydration energy and the adsorption energy into the MHCF [23]. The transition metal of the MHCF material also influences their ability as ionic sieve [24, 25]. Additional key aspect refers to the abundance of the metal and safety concerns. Among MHCFs, zinc, manganese, and iron analogues are characterized by low toxicity and low cost, therefore making them promising systems for development in several industrial applications [26, 27]. In particular, zinc hexacyanoferrate ( $\mathrm{ZnHCF}$ ) is one of the MHCFs used in aqueous ion battery improvement, thanks to its very high operating potential [28]. As shown in Table 1, the precursor salt $\mathrm{ZnCl}_{2}$ has a LD50 of $350 \mathrm{mg} / \mathrm{kg}$, and relatively cheap while compared to other transition metal chloride salts [22]. LD50, lethal dose or median lethal dose, is defined as the amount of a toxic agent lethal to the $50 \%$ of the experimental animals exposed to it. However, although procedures for the deposition of zinc hexacyanoferrate film are available, there is a lack of deposition protocol on the common electrode support (glassy carbon electrode) [29]. For instance, Fenga and Stradiotto suggest a controlled electrodeposit procedure of $\mathrm{ZnHCF}$ on piezoelectric quartz crystal [30] and the $\mathrm{ZnHCF}$ preparation on graphiteepoxy composite [31]. Eftekhari [32] reported the dependence of the formal potential values in different supporting electrolytes and the electrocatalytic activity of ZnHCF obtained by a direct modification of the $\mathrm{Zn}$ electrode. Several procedures of chemical modification of an electrode are reported as well. Joseph et al. [33] studied the behavior of ZnHCF on waximpregnated graphite electrode, evaluating the influence of the $\mathrm{Zn}^{2+}$ and ferricyanide salt ratio on electrosynthesis step as well as the electrochemical behavior in different supporting electrolytes. Kemmegne-Mbouguen et al. [34] investigate the clay-zinc hexacyanoferrate carbon paste electrode as sensor for uric acid, dopamine, and tryptophan.

This work reports a facile approach to a stable modification of GCE by ZnHCF, obtaining a well-defined redox couple with a formal potential of about $+1.0 / 0.8 \mathrm{~V}$ assigned to the redox couples $\left[\mathrm{K}_{2} \mathrm{ZnFe}^{\mathrm{II}}(\mathrm{CN})_{6}\right] /\left[\mathrm{KZnFe}^{\mathrm{III}}(\mathrm{CN})_{6}\right]$. Furthermore, $\mathrm{ZnHCF}$ was investigated in different support electrolytes, in order to highlight its capability as ionic sieve.

\section{Experimental}

\section{Materials}

Chemicals were reagent grade from Sigma-Aldrich ${ }^{\circledR}$ $\left(\mathrm{K}_{3} \mathrm{Fe}(\mathrm{CN})_{6}-244,023, \mathrm{H}_{3} \mathrm{BO}_{3}-\mathrm{B} 0394, \mathrm{KCl}-\mathrm{P} 3911\right.$, $\left.\mathrm{SrCl}_{2}-255,521, \mathrm{CaCl}_{2}-223,506, \mathrm{Al}\left(\mathrm{NO}_{3}\right)_{3}-237,973\right)$ and from Carlo Erba reagents ${ }^{\circledR}$ (NaCl-612000600,
LiCl-458256, $\mathrm{ZnCl}_{2}-494,105, \mathrm{MgCl}_{2}$-459,336, $\left.\mathrm{BaCl}_{2}-425,026, \mathrm{CrCl}_{3}-440,724\right)$ used without any further purification. All experiments have been performed in air, at room temperature and with bi-distilled water.

\section{Apparatus}

Electrochemical measurements were performed with a Model 730e (CH Instruments) electrochemical workstation using a standard three-electrode electrochemical glass cell $(10 \mathrm{ml})$. The substrate of the working electrode was glassy carbon, GC (diameter $3 \mathrm{~mm}$ ) or graphite foil, GF $(0.10 \mathrm{~mm}$ thick, 99.9\%, Goodfellow), and a Pt counter electrode was used. All potentials were reported vs $\mathrm{Ag} / \mathrm{AgCl}$ reference electrode in saturated $\mathrm{KCl}$.

\section{Preparation of modified electrode}

ZnHCF films were obtained by a double-step electrosynthesis: firstly, it was modified by an electrochemical deposition from a $0.5 \mathrm{M} \mathrm{ZnCl}_{2}$ and $0.4 \mathrm{M} \mathrm{H}_{3} \mathrm{BO}_{3}$ solution [35] cycled between -0.80 and -1.2 V. (Fig. 1A); the ZnGCE was soaked in a $10 \mathrm{mM}$ solution of $\mathrm{K}_{3} \mathrm{Fe}(\mathrm{CN})_{6}$ and $0.1 \mathrm{M} \mathrm{KCl}$ for about $10 \mathrm{~min}$. Then it was dried at room temperature. The film characterization was carried out in $1.0 \mathrm{M}-1.0 \times 10^{-2} \mathrm{M} \mathrm{KCl}$ solutions to investigate the support electrolyte concentration effect.

The electrochemical behavior in presence of different monovalent, divalent, and trivalent metal cations was investigated by recording CVs in various supporting electrolytes following the protocol: firstly, a CV was recorded in a $\mathrm{KCl} 0.1 \mathrm{M}$, then a $\mathrm{CV}$ was recorded in other cation $0.1 \mathrm{M}$ solution, and finally, a last $\mathrm{CV}$ scan was repeated in $0.1 \mathrm{M} \mathrm{KCl} \mathrm{[16].}$

\section{Physical characterization}

To perform SEM and ATR-FTIR analysis, ZnHCF was deposited on graphite foil following the protocol described in the "Experimental" section used for GCE modification. Briefly, the oxidized electrode (ZnHCFO) was obtained potentiodynamically by applying a linear sweep from OCP to $+1.2 \mathrm{~V}$ in $\mathrm{KCl} 0.1 \mathrm{M}$, while the reduced electrode $(\mathrm{ZnHCF}-\mathrm{R})$ from $\mathrm{OCP}$ to $+0.4 \mathrm{~V}$, in the same electrolyte.
Table. 1 Cost and LD50 (rat, oral) of some metal chlorides From reference [22]

\begin{tabular}{llllllll}
\hline & $\mathbf{B a C l}_{\mathbf{2}}$ & $\mathbf{C o C l}_{\mathbf{2}}$ & $\mathbf{C u C l}_{\mathbf{2}}$ & $\mathbf{M n C l}_{\mathbf{2}}$ & $\mathbf{N i C l}_{\mathbf{2}}$ & $\mathbf{S n C l}_{\mathbf{2}}$ & $\mathbf{Z n C l}_{\mathbf{2}}$ \\
\hline $\mathrm{LD} 50\left(\mathrm{mg} \mathrm{kg}^{-1}\right)$ & 118 & 80 & 584 & 1484 & 105 & 700 & $\mathbf{3 5 0}$ \\
Price $\left(€ \mathrm{~kg}^{-1}\right)$ & 45 & 1272 & 174 & 199 & 904 & 148 & $\mathbf{1 2 2}$ \\
\hline
\end{tabular}



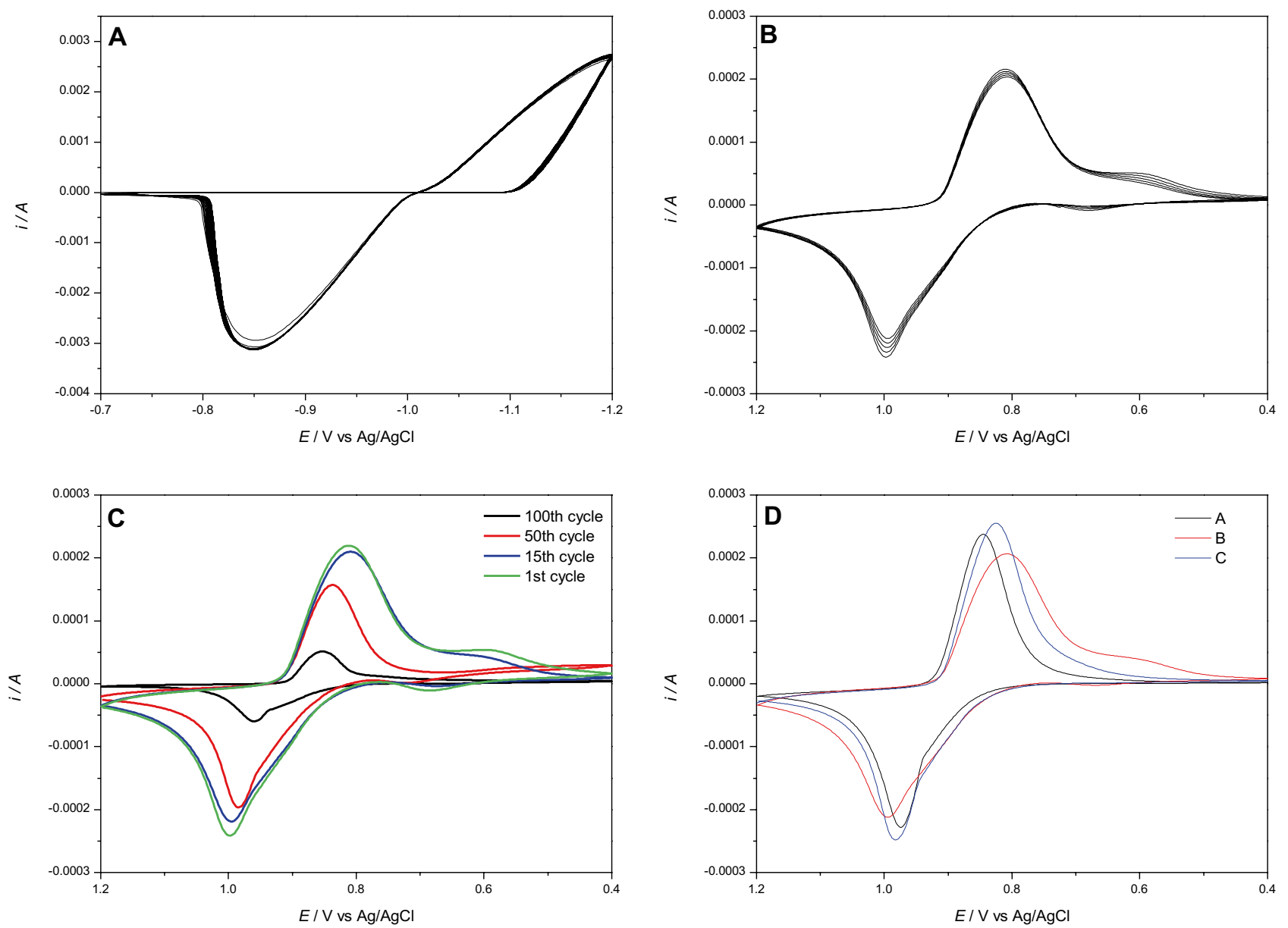

Fig. 1 A CV of zinc electrodeposited on GCE; B CV of ZnHCF-GC modified electrode at $0.1 \mathrm{~V} \mathrm{~s}^{-1}$ in a $0.1 \mathrm{M} \mathrm{KCl}$ solution-10 cycles; C CV of ZnHCF film: 1st cycle, 15th cycle, 50th cycle, and 100th

\section{ATR-FTIR}

IR spectra were recorded from 4000 to $400 \mathrm{~cm}^{-1}$ on a PerkinElmer Frontier FT-IR instrument, equipped with single reflection ATR unit (universal diamond ATR top-plate) as a sample support.

\section{SEM}

SEM experiments were performed on a field emission scanning electron microscope (FESEM) ZEISS SIGMA 300.

\section{Results and discussion}

\section{ZnHCF electrochemical characterization}

Zinc hexacyanoferrate films were obtained on a GCE following the double-step electrosynthesis protocol detailed in the "Experimental section." The soaking of Zn-modified GCE

cycle recorded; and $\mathbf{D}$ first cycles of $\mathrm{ZnHCF}$ film $\mathrm{CV}$ response for three different electrodes

in a $\mathrm{K}_{3} \mathrm{Fe}(\mathrm{CN})_{6}$ solution causes the redox reaction in about $10 \mathrm{~min}$. It takes place on the surface of the electrode, with the conversion of zinc to potassium zinc hexacyanoferrate, as follows:

$$
\begin{array}{r}
3 \mathrm{Zn}^{0}+6 \mathrm{~K}_{3} \mathrm{Fe}^{I I I}(\mathrm{CN})_{6}+\chi \mathrm{H}_{2} \mathrm{O} \leftrightarrows \mathrm{K}_{2} \mathrm{Zn}_{3} \\
{\left[\mathrm{Fe}^{I I}(\mathrm{CN})_{6}\right]_{2} \chi \mathrm{H}_{2} \mathrm{O}+4 \mathrm{~K}_{4} F \mathrm{e}^{I I}(\mathrm{CN})_{6}}
\end{array}
$$

The ZnHCF films on GCE were characterized in a $0.1 \mathrm{M}$ $\mathrm{KCl}$ solution by cyclic voltammetry. Voltammograms show the $\mathrm{K}_{2} \mathrm{Zn}_{3}\left[\mathrm{Fe}^{\mathrm{II}}(\mathrm{CN})_{6}\right]_{2} / \mathrm{KZn}_{3}\left[\mathrm{Fe}^{\mathrm{III}}(\mathrm{CN})_{6}\right]_{2}$ reversible redox couple with a formal potential of about $+0.9 \mathrm{~V}$ vs $\mathrm{Ag} / \mathrm{AgCl}$ and a steady current density for the first $30 \mathrm{seg}$ ments (Fig. 1B). The CV shape is characterized also by the weak anodic and cathodic peaks at approximately $0.65 \mathrm{~V}$. As reported, this particular morphology is due to the cubic structure [23] that is confirmed also by the SEM analysis ("Physico-chemical characterization of ZnHCF films" section). Furthermore, the stability of the film by repeated CV scans at $0.1 \mathrm{~V} \mathrm{~s}^{-1}$ was checked. The intensity of the cathodic 
and anodic peak current is stable until the 15th cycle, then it decreases gradually until 50th cycle, and the last cycles are characterized by a fast decrease of the current with the number of the cycles (Fig. 1C). The procedure, described in the "Experimental section," was tested several times obtaining charge values with a RSD \% of 21 . The data is affected by the electrochemical control lacking during the deposition.

The stickiness was ensured by the electrode drying at room temperature, whereas the electrode rinsing was a precondition to obtain a well-defined peak. Three ZnHCF film comparable CV responses were shown in Fig. 1D, with similar peak current values. The current involved in the process is closely related to the amount of the electroactive material originated from the reaction taking place on the electrode surface during the soaking step. The calculated surface coverage value was $1.46 \times 10^{-08} \mathrm{~mol} / \mathrm{cm}^{2}$, considering the average charge value of the first five CVs.

ZnHCF films were characterized using different concentrations of a $\mathrm{KCl}$ solution, and the results are reported in Fig. 2. This test reveals the role of the potassium cation in the redox reaction, based on Nerstian equation for a solid film:

$\mathrm{K}_{2} \mathrm{Zn}_{2}\left[\mathrm{Fe}^{\mathrm{III}}(\mathrm{CN})_{6}\right]_{2}+\mathrm{K}^{+}+\mathrm{e}^{-} \leftrightarrows \mathrm{K}_{3} \mathrm{Zn}_{2}\left[\mathrm{Fe}^{\mathrm{II}}(\mathrm{CN})_{6}\right]_{2}$

$E=k+0.059 \log \left[a_{k+}\right]$

According to Eq. (4), Fig. 2 shows linear dependence of the two variables (E cathodic vs $\log$ of $\mathrm{KCl}$ solution concentration) with a slope of about $68 \mathrm{mV}$, close to theoretical value of $59 \mathrm{mV}$. This, in turn, confirms a Nerstian behavior and a one-electron transfer reaction. In addition, the effect of other supporting electrolytes was investigated; the results are shown in the "ZnHCF as ionic sieves" section.

Figure 3B shows the characterization of the $\mathrm{ZnHCF}$ electrode in terms of anodic current dependence to the scan rate. Specifically, the CVs of ZnHCF-GCE at several scan rates are displayed in Fig. 3A. The curves highlighted that the decreasing of the scan rate causes a decreasing of the anodic and cathodic peaks, as expected, and a shifting of $E^{0}$. A checking of the power-law relationship with the scan rate, i.e., $i=a v^{\mathrm{b}}$ where $i$ is the current of anodic and cathodic peaks, $v$ is the scan rate, and $a$ and $b$ are the experimental parameters, is shown in the panel B of Fig. 3. The panel displays two different slopes for the $\log (v)-\log (i)$ plot, where $\mathrm{b}$ value is about 0.5 at higher scan rate underling a diffusioncontrolled process, whereas $b$ is quoted around 1 at low scan rate, indicating a surface-controlled process. Therefore, the $\mathrm{K}^{+}$insertion/de-insertion processes are surface-controlled at lower scan rates and diffusion-controlled at higher ones. In light of this evidence, we consider that $100 \mathrm{mVs}^{-1}$ is a suitable scan rate to investigate $\mathrm{ZnHCF}$ capability as ionic sieve, which ensure the occurrence of a diffusion-controlled process. Similar results were reported by Eftekhari and Joseph et al. [32, 33], who studied the effect of the support electrolytes at high scan rate and at low scan rate, respectively. Eftekhari reported the effect of the support electrolytes on the voltammogram shape and formal potential shifting of the
Fig. 2 Potential vs $\log \left[\mathrm{K}^{+}\right]$of ZnHCF-GC modified electrode

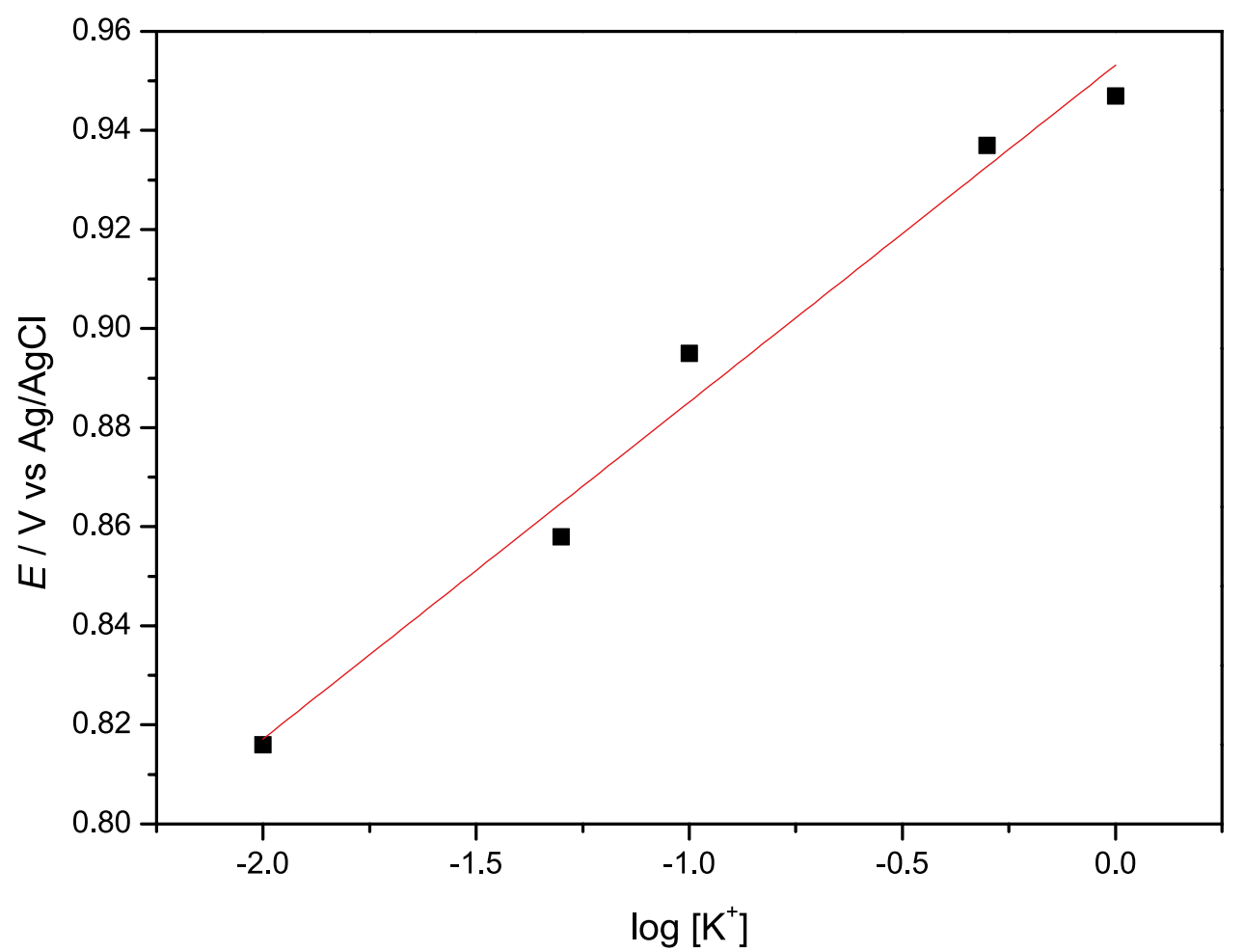



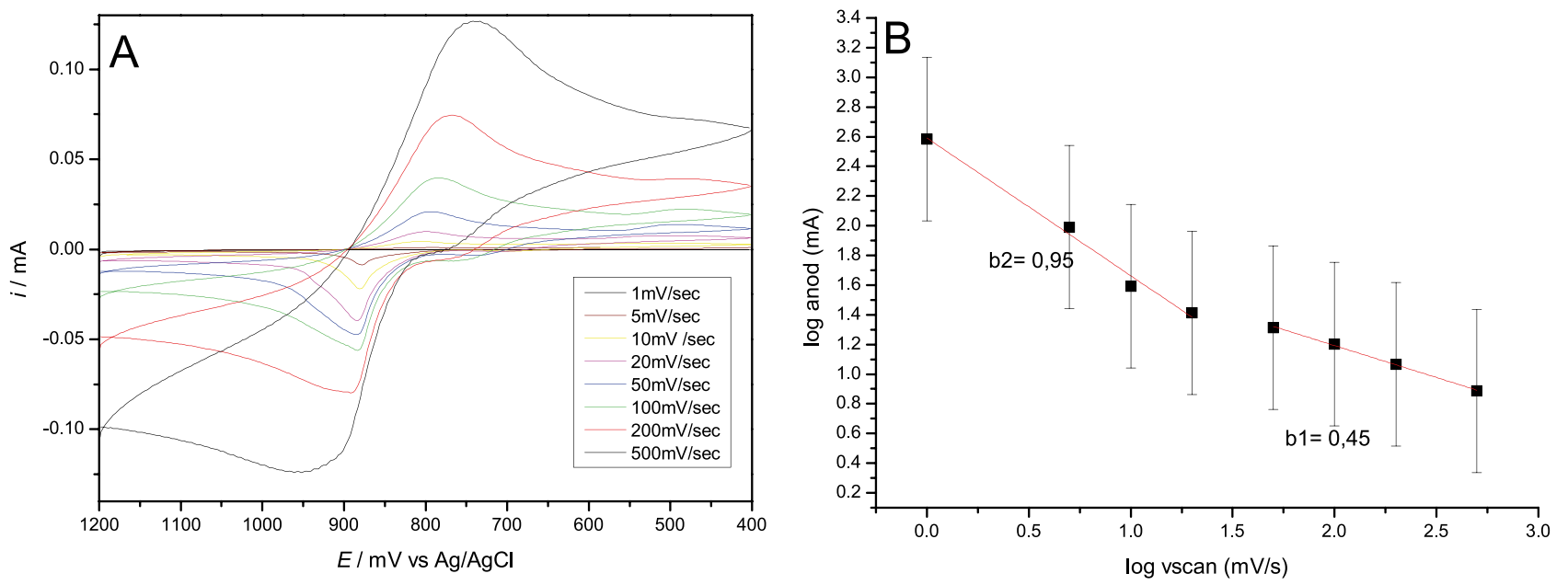

Fig. 3 A ZnHCF-GC modified electrode at several scan rate in $\mathrm{KCl} 0.1 \mathrm{M}$ and $\mathbf{B}$ relation between $\log \mathrm{ip}_{\mathrm{A}}(\mathrm{mA})$ and $\log \mathrm{scan}$ rate $(\mathrm{mV} / \mathrm{s})$

ZnHCF chemically modified electrode, testing several alkali cations, while Joseph et al. focused on surface processes of a ZnHCF wax-impregnated graphite electrode

\section{Physico-chemical characterization of ZnHCF films}

The ZnHCF was electrodeposited on grafoil following the same experimental protocol, in order to be investigated by SEM and ATR-FTIR spectroscopy. For this purpose, two different electrodes were analyzed: $\mathrm{ZnHCF}-\mathrm{O}$, referring to the oxidized electrode and ZnHCF-R to the reduced one.

SEM characterization reveals a surface morphology composed of poly-dispersed particles that are aggregated to form a porous network. The ZnHCF samples consist of size-heterogeneous particles, of about 100-300 nm (Fig. 4C), although some particles are bigger (Fig. 4B). The morphology is characterized by cubic particles which are pointed out distinctly, at a nanometric level as well. The cubes visible in the figure can be related to the cubic structure of zinc hexacyanoferrate. The morphologies displayed in Fig. 4A, B, for the ZnHCF-R and ZnHCF-O, respectively, confirms a similar behavior of the modified electrode. Therefore, the potentiodynamic modification does not affect the overall shape and morphology of the films.

FTIR characterization provides useful information on the oxidation state of the studied compounds. The ATR-FTIR spectra of the oxidized and reduced electrodes are represented in Fig. 5. All samples show a broad band of the $v_{\mathrm{CN}}$ adsorption at about $2000-2200 \mathrm{~cm}^{-1}$, as expected for bimetallic cyanide $\mathrm{Fe}-\mathrm{C}-\mathrm{N}-\mathrm{Zn}$, which can be used as a fingerprint of the oxidation state. A close inspection of the figure reveals that the spectrum recorded for ZnHCF-O shows a band at $2096 \mathrm{~cm}^{-1}$, which is close to the band at $2091 \mathrm{~cm}^{-1}$ founded for $\mathrm{Fe}^{\mathrm{II}}-\mathrm{C}-\mathrm{N}-\mathrm{Zn}^{\mathrm{II}}$ system [36]. In addition, the insert in the figure displays a couple of broad peaks at $489 \mathrm{~cm}^{-1}$ and
$603 \mathrm{~cm}^{-1}$ which are related to $\mathrm{Zn}-\mathrm{N}$ and $\mathrm{Fe}-\mathrm{C}$ stretching, respectively. Lastly, peaks at $1622 \mathrm{~cm}^{-1}$ and $3620 \mathrm{~cm}^{-1}$ are due to the presence of $\mathrm{OH}$ from water molecules.

\section{ZnHCF as ionic sieves}

A precise protocol was followed to investigate the $\mathrm{ZnHCF}$ GCE electrochemical behavior in several monovalent, divalent, and trivalent cations in order to evaluate the affinity of the tested cations compared to $\mathrm{K}^{+}$: the first $\mathrm{CV}$ was recorded in $0.1 \mathrm{M} \mathrm{KCl}$, the second $\mathrm{CV}$ was recorded in $0.1 \mathrm{M}$ of cation tested, and finally the last $\mathrm{CV}$ was repeated in $0.1 \mathrm{M}$ $\mathrm{KCl}[16]$.

The CVs of ZnHCF-GCE were studied in different support electrolyte cations in addition to $\mathrm{K}^{+}$. The results are shown in Fig. 6A (all cations), B (monovalent cations), C (divalent cations), and D (trivalent cations).

The various cation species cause a potential shifting and a peak shape variation (Fig. 6A). This behavior has been reported for other MHCFs [37-39] and rationalized in terms of cation overall dimension. An insertion/de-insertion mobility order of monovalent cations was reported for ZnHCF film, and potassium shows the best cation mobility [33]. Figure 6B, C, and D show the ZnHCF film capability to intercalate/de-intercalate, respectively, monovalent, divalent, and trivalent cations compared to $\mathrm{K}^{+}$. The perfect reversibility of the process is confirmed for all the cations, by the $\mathrm{CV}$ recorded in $\mathrm{K}^{+}$before and after the $\mathrm{CV}$. There is almost complete match of the pristine and of the recovered CVs in potassium salt, also in terms of peak current. This unambiguously suggest that $\mathrm{ZnHCF}$ film here reported has the capacity to exchange monovalent, divalent, and trivalent cations with high efficiency.

Kinetics of the exchange was also investigated, and our experimental data suggests that the uptake of divalent or 

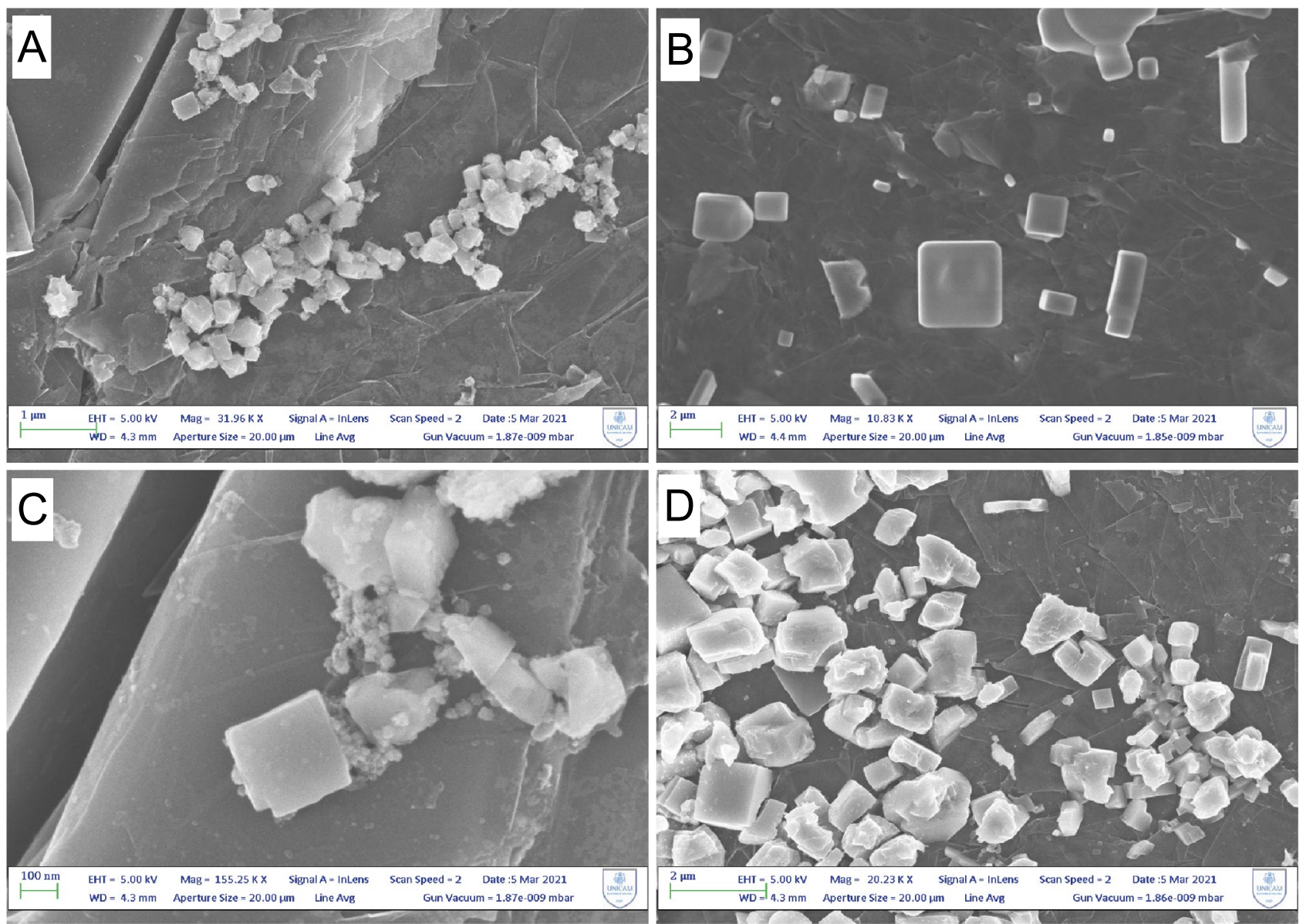

Fig. 4 SEM micrographs of ZnHCF-modified electrodes: A and D ZnHCF-R at different magnification and $\mathbf{B}$ and $\mathbf{C}$ ZnHCF-O at different magnification

Fig. 5 ATR-FTIR spectra of $\mathrm{ZnHCF}-\mathrm{O}$ and $\mathrm{ZnHCF}-\mathrm{R}$ on graphite foil

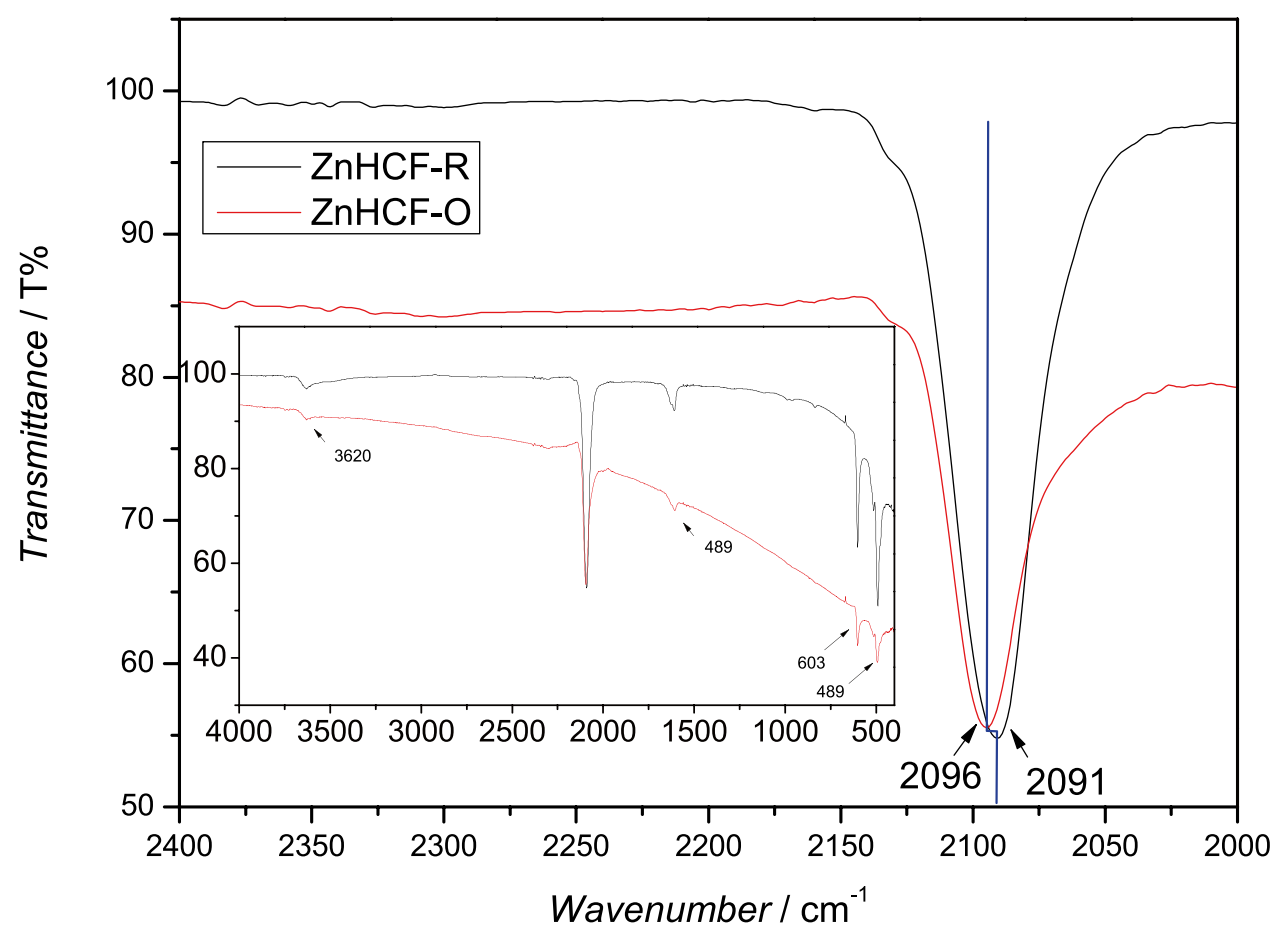



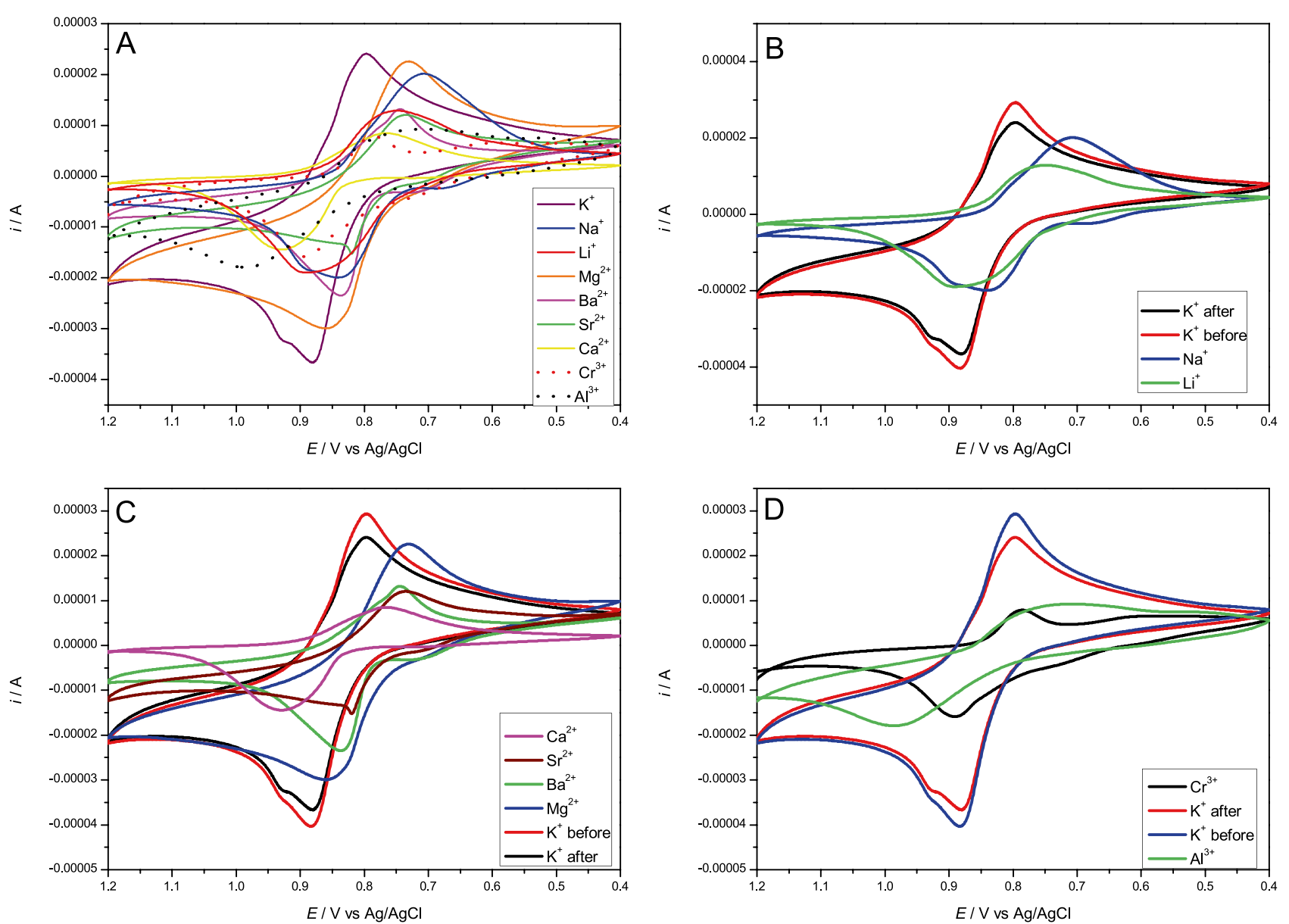

Fig. $6 \mathrm{CVs}$ of $\mathrm{ZnHCF}$ film in $\mathbf{A} 0.1 \mathrm{M} \mathrm{LiCl}, \mathrm{NaCl}, \mathrm{MgCl}_{2}, \mathrm{CaCl}_{2}$, $\mathrm{SrCl}_{2}, \mathrm{BaCl}_{2}, \mathrm{CrCl}_{3}, \mathrm{Al}\left(\mathrm{NO}_{3}\right)_{3}$, and $\mathrm{KCl}$ before and after exchanges; B in $0.1 \mathrm{M} \mathrm{KCl}$ before and after $0.1 \mathrm{M} \mathrm{LiCl}$ and $\mathrm{NaCl}$; $\mathbf{C}$ in $0.1 \mathrm{M}$

$\mathrm{KCl}$ before and after $0.1 \mathrm{M} \mathrm{MgCl}_{2}, \mathrm{CaCl}_{2}, \mathrm{SrCl}_{2}$, and $\mathrm{BaCl}_{2}$; and $\mathbf{D}$ in $0.1 \mathrm{M} \mathrm{KCl}$ before and after $0.1 \mathrm{M} \mathrm{CrCl}_{3}$ and $\mathrm{Al}\left(\mathrm{NO}_{3}\right)_{3}$

Fig. $7 \mathrm{ZnHCF}$ film in $\mathrm{KCl}$ $0.1 \mathrm{M}$ (black line), $\mathrm{CaCl}_{2} 0.1 \mathrm{M}$ (blue line), and $\mathrm{KCl} 0.1 \mathrm{M}$ after $\mathrm{CaCl}_{2}$ (red line)

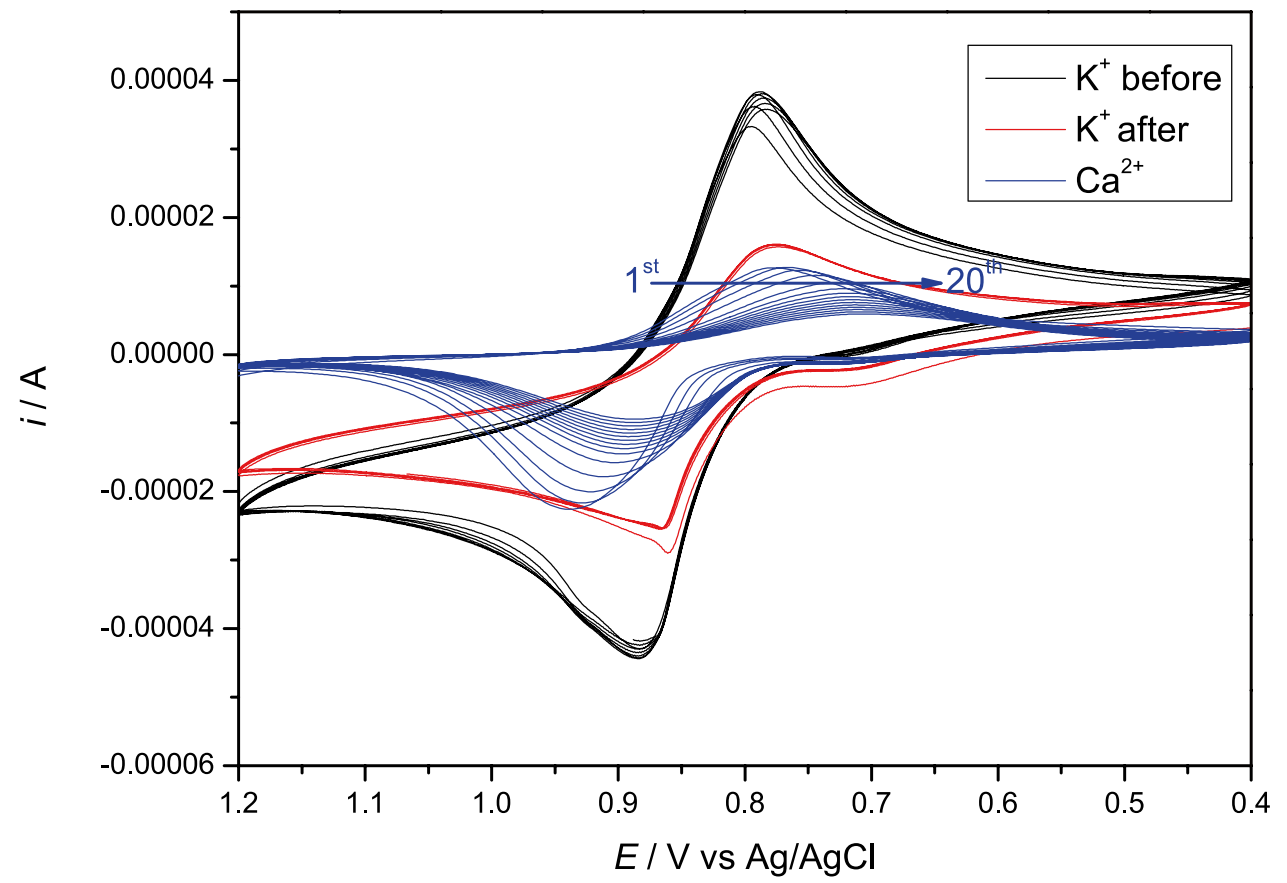


Fig. 8 Variation of $\mathrm{ZnHCF}$ potential and hydrated radius of $\mathrm{Li}, \mathrm{Na}$, and $\mathrm{K}$

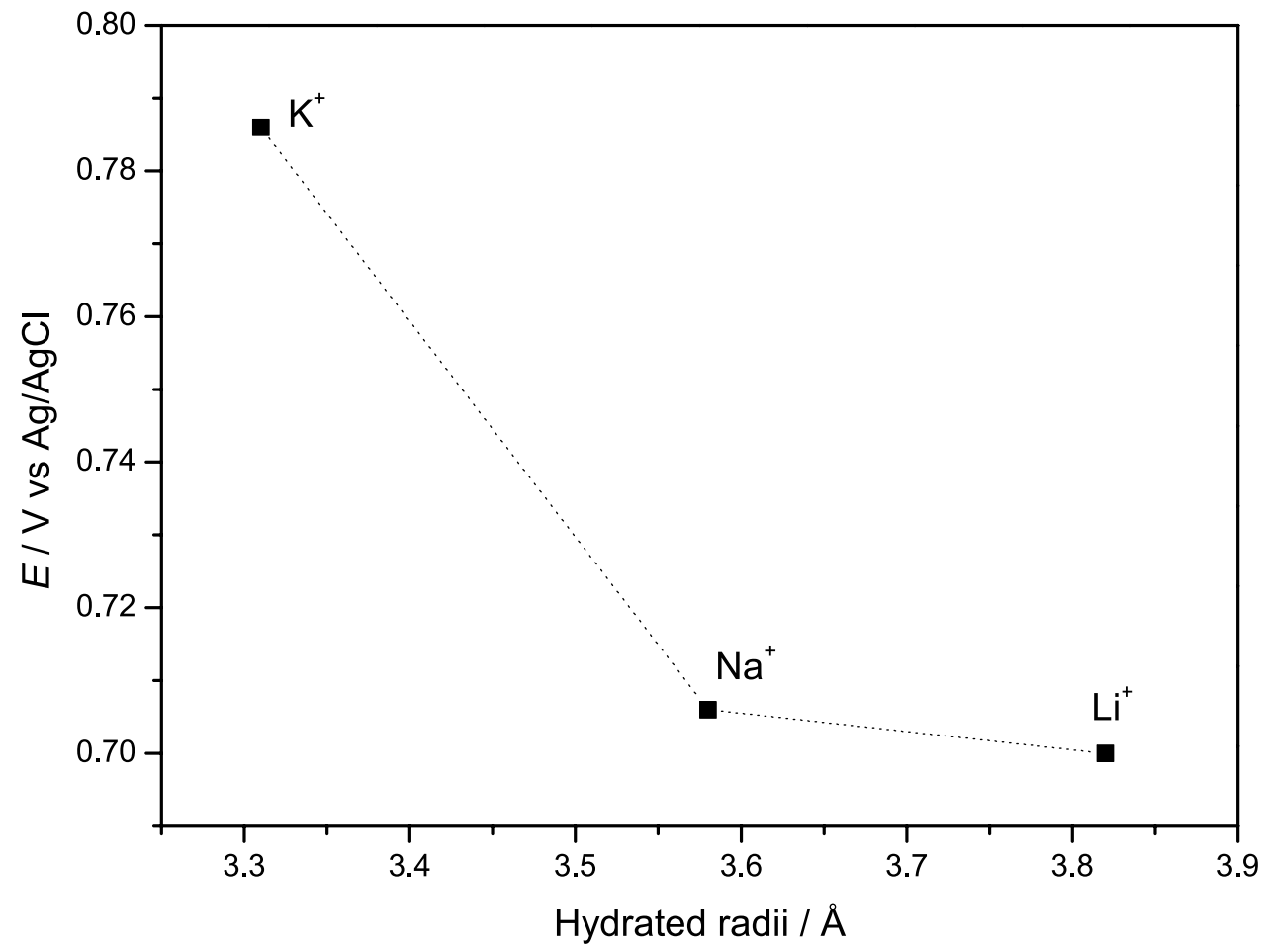

trivalent ions is slower than the uptake of the potassium. For example, Fig. 7 shows the CVs of ZnHCF recorded in $\mathrm{KCl} 0.1 \mathrm{M}$, in $\mathrm{CaCl}_{2} 0.1 \mathrm{M}$, and then back to $\mathrm{KCl}$. Unlike the $\mathrm{CV}$ related to the re-uptake of $\mathrm{K}^{+}$ion, the $\mathrm{CV}$ recorded during the insertion of $\mathrm{Ca}^{2+}$ shows a potential shift from the first segment to the steady last ones. A similar behavior does not occur for the potassium insertion; in fact, the voltammogram (Fig. 7) is characterized by the overlapping segments. Therefore, these processes are controlled by kinetics and the uptake of divalent and trivalent cations takes place slowly, whereas smaller radii cations were exchanged easily. Although the channel diameter for metal hexacyanoferrates is similar and close to $320 \mathrm{pm}$, the cationic radii influence

Table. 2 Ionic and hydrated radii and cathodic and anodic potential of different cations tested

\begin{tabular}{lllll}
\hline & $\begin{array}{l}\text { Ionic radii } \\
\boldsymbol{r}_{\boldsymbol{x}}(\stackrel{\AA}{\mathbf{A}})[42]\end{array}$ & $\begin{array}{l}\text { Hydrated } \\
\text { ionic radii } \boldsymbol{r}_{\boldsymbol{h}} \\
(\mathbf{\AA})[42]\end{array}$ & $\begin{array}{l}\text { Cathodic } \\
\text { potential (V) } \\
\text { vs Ag/AgCl }\end{array}$ & $\begin{array}{l}\text { Anodic } \\
\text { potential (V) } \\
\text { vs Ag/AgCl }\end{array}$ \\
\hline $\mathrm{Li}^{+}$ & 0.6 & 3.82 & 0.700 & -0.870 \\
$\mathrm{Na}^{+}$ & 0.95 & 3.58 & 0.706 & -0.838 \\
$\mathrm{~K}^{+}$ & 1.33 & 3.31 & 0.786 & -0.881 \\
$\mathrm{Mg}^{+}$ & 0.65 & 4.28 & 0.713 & -0.858 \\
$\mathrm{Ca}^{+2}$ & 0.99 & 4.12 & 0.707 & -0.896 \\
$\mathrm{Sr}^{+2}$ & 1.13 & 4.12 & 0.698 & -0.801 \\
$\mathrm{Ba}^{+2}$ & 1.35 & 4.04 & 0.722 & -0.828 \\
$\mathrm{Al}^{+3}$ & 0.5 & 4.75 & 0.723 & -0.988 \\
$\mathrm{Cr}^{+3}$ & 0.64 & 4.61 & 0.774 & -0.870 \\
\hline
\end{tabular}

the potential shift and also the attitude of each ion to be inserted and de-inserted [40].

Figure 8 shows the relationship between radii size (hydrated radius) of alkali cations and the $\mathrm{ZnHCF}$ intercalation potential. It decreases with the hydrated radii size (in details in Table 2), following the order $\mathrm{K} \gg \mathrm{Na}>\mathrm{Li}$, as also accepted for other MHCFs [41]. ZnHCF easily hosts alkali earth cations as well. The diffusion coefficients $\left(\mathrm{D}_{a p p}\right)$ were calculated by the Ip vs $v^{1 / 2}$ slope. As shown in Table 3, potassium $\mathrm{D}_{a p p}$ is by far the highest as described by the potential vs hydrated radius. As a matter of fact, $\mathrm{Li}^{+}$shows a faster diffusion then $\mathrm{Na}^{+}$into $\mathrm{ZnHCF}$, even though their $\mathrm{D}_{a p p}$ values are comparable. The CVs (Fig. 6C) show a good reversible process in spite of the increasing of ionic radii size of the cations accommodated into the structure. As matter of fact, the lattice might go to microstructural distortions. Ions with smaller ionic radii have larger hydrated radii so they hold on their hydration shells. On the other hand, larger radii ions are less strongly hydrated; therefore, they able to break off their hydration shells during the insertion into the ZnHCF lattice. Similar CVs of the Fig. 7 for monovalent and divalent ions are available as supporting information.

Table. 3 Diffusion coefficient $\left(\mathrm{D}_{a p p}\right)$ of alkali cation ( $0.1 \mathrm{M}$ solution) in the $\mathrm{ZnHCF}$ film, obtained from $\mathrm{CV}$ at high scan rates

\begin{tabular}{llll}
\hline Cation & $\mathrm{Li}^{+}$ & $\mathrm{Na}^{+}$ & $\mathrm{K}^{+}$ \\
\hline $10^{-8} \mathrm{D}_{\text {app }}$ rid $\left(\mathrm{cm}^{2} \mathrm{~s}^{-1}\right)$ & 3.66 & 1.67 & 8.56 \\
$10^{-8} \mathrm{D}_{\text {app }}$ ox $\left(\mathrm{cm}^{2} \mathrm{~s}^{-1}\right)$ & 5.08 & 3.28 & 6.02 \\
\hline
\end{tabular}




\section{Conclusions}

Films of zinc hexacyanoferrate have been deposited on a glassy carbon electrode with a specific protocol aimed at ensuring reproducible electrode characteristics. The morphology of the electrodeposited material has been further studied by SEM and ATR-FTIR spectroscopy confirming the occurrence of the $\mathrm{Fe}^{\mathrm{II}}-\mathrm{C}-\mathrm{N}-\mathrm{Zn}^{\mathrm{II}}$ structural unit. A full electrochemical characterization suggested a good stability of the film and the capacity to intercalate several both monovalent and divalent cations. Kinetics of the intercalation/deintercalation process has been also addressed. Overall, the low-toxicity and cheapness zinc make zinc hexacyanoferrate films a promising candidate for application in ion exchange system.

Author contribution All authors contributed to the study conception and design. Material preparation, data collection, and analysis were performed by Rosalinda Sciacca. The first draft of the manuscript was written by Rosalinda Sciacca and Marco Giorgetti, and all authors commented on previous versions of the manuscript. All authors read and approved the final manuscript.

Funding Open access funding provided by Alma Mater Studiorum Università di Bologna within the CRUI-CARE Agreement.

Open Access This article is licensed under a Creative Commons Attribution 4.0 International License, which permits use, sharing, adaptation, distribution and reproduction in any medium or format, as long as you give appropriate credit to the original author(s) and the source, provide a link to the Creative Commons licence, and indicate if changes were made. The images or other third party material in this article are included in the article's Creative Commons licence, unless indicated otherwise in a credit line to the material. If material is not included in the article's Creative Commons licence and your intended use is not permitted by statutory regulation or exceeds the permitted use, you will need to obtain permission directly from the copyright holder. To view a copy of this licence, visit http://creativecommons.org/licenses/by/4.0/.

\section{References}

1. Chillawar RR, Tadi KK, Motghare RV (2015) Voltammetric techniques at chemically modified electrodes. J Anal Chem 70:399-418

2. Murray RW, Ewing AG, Durst RA (1987) Chemically modified electrodes molecular design for electroanalysis. Anal Chem 59:379A-390A

3. Kimmel DW, LeBlanc G, Meschievitz ME, Cliffel DE (2012) Electrochemical sensors and biosensors. Anal Chem 84:685-707

4. Isfahani VB, Memarian N, Dizaji HR et al (2019) The physical and electrochromic properties of Prussian Blue thin films electrodeposited on ITO electrodes. Electrochim Acta 304:282-291

5. Mullaliu A. Giorgetti M (2019) Metal hexacyanoferrates: ion insertion (or exchange) capabilities. In: Inamuddin. Ahamed MI. Asiri AM (eds) Applications of Ion Exchange Materials in the Environment. Springer International Publishing. Cham. pp 109-133
6. Mortimer RJ, Rosseinsky DR (1983) Electrochemical polychromicity in iron hexacyanoferrate films, and a new film form of ferric ferricyanide. J Electroanal Chem Interfacial Electrochem 151:133-147

7. Shan Y, Yang G, Gong J et al (2008) Prussian blue nanoparticles potentiostatically electrodeposited on indium tin oxide/chitosan nanofibers electrode and their electrocatalysis towards hydrogen peroxide. Electrochim Acta 53:7751-7755

8. Zadronecki M, Wrona PK, Galus Z (1999) Study of growth and the electrochemical behavior of Prussian Blue films using electrochemical quartz crystal microbalance. J Electrochem Soc 146:620-627

9. Giorgetti M, Scavetta E, Berrettoni M, Tonelli D (2001) Nickel hexacyanoferrate membrane as a coated wire cation-selective electrode. Analyst 126:2168-2171

10. Pasta M, Wessells CD, Liu N et al (2014) Full open-framework batteries for stationary energy storage. Nat Commun 5:3007

11. Park SI, Gocheva I, Okada S, Yamaki J (2011) Electrochemical properties of $\mathrm{NaTi}_{2}\left(\mathrm{PO}_{4}\right)_{3}$ anode for rechargeable aqueous sodiumion batteries. J Electrochem Soc 158:A1067

12. Mullaliu A, Asenbauer J, Aquilanti G et al (2020) Highlighting the reversible manganese electroactivity in Na-rich manganese hexacyanoferrate material for Li- and Na-ion storage. Small Methods 4:1900529

13. Lilga MA, Orth RJ, Sukamto JPH et al (2001) Cesium separation using electrically switched ion exchange. Sep Purif Technol 24:451-466

14. Ciabocco M, Berrettoni M, Zamponi S et al (2018) An overview on the facile and reversible cations intercalation in nickelhexacyanoferrate open framework. Int J Electrochem Sci 5535-5551

15. Wang RY, Shyam B, Stone KH et al (2015) Reversible multivalent (monovalent, divalent, trivalent) ion insertion in open framework materials. Adv Energy Mater 5:1401869

16. Ciabocco M, Berrettoni M, Zamponi S et al (2013) Electrochemical behavior of Inhcf in alkali metal electrolytes. J Solid State Electrochem 17:2445-2452

17. Chen R, Tanaka H, Kawamoto T et al (2013) Selective removal of cesium ions from wastewater using copper hexacyanoferrate nanofilms in an electrochemical system. Electrochim Acta 87:119-125

18. Prout WE, Russell ER, Groh HJ (1965) Ion exchange absorption of cesium by potassium hexacyanocobalt (II) ferrate (II). J Inorg Nucl Chem 27:473-479

19. Ding D, Lei Z, Yang Y et al (2014) Selective removal of cesium from aqueous solutions with nickel (II) hexacyanoferrate (III) functionalized agricultural residue-walnut shell. J Hazard Mater 270:187-195

20. Parajuli D, Takahashi A, Noguchi H et al (2016) Comparative study of the factors associated with the application of metal hexacyanoferrates for environmental Cs decontamination. Chem Eng J 283:1322-1328

21. Jang SC, Hong SB, Yang HM et al (2014) Removal of radioactive cesium using Prussian Blue magnetic nanoparticles. Nanomaterials 4:894-901

22. Gromadskyi D, Chervoniuk V, Kirillov S (2016) Cyclic voltammetric study of tin hexacyanoferrate for aqueous battery applications. J Electrochem Sci Eng 6:225-234

23. Ni G, Han B, Li Q et al (2016) Instability of zinc hexacyanoferrate electrode in an aqueous environment: redox-induced phase transition, compound dissolution, and inhibition. ChemElectroChem 3:798-804

24. Asai M, Takahashi A, Tajima K et al (2018) Effects of the variation of metal substitution and electrolyte on the electrochemical reaction of metal hexacyanoferrates. RSC Adv 8:37356-37364

25. Malik MA, Kulesza PJ, Marassi R et al (2004) Countercation intercalation and kinetics of charge transport during redox reactions of nickel hexacyanoferrate. Electrochim Acta 49:4253-4258 
26. Lu Y, Wang L, Cheng J, Goodenough JB (2012) Prussian blue: a new framework of electrode materials for sodium batteries. Chem Commun 48:6544-6546

27. Shen L, Wang Z, Chen L (2014) Prussian Blues as a cathode material for lithium ion batteries. Chem Eur J 20:12559-12562

28. Do Carmo DR, Rodrigues FDW, Filho UP et al (2001) The cyanide photoisomerization in zinc hexacyanoferrate (II) supported on titanium dioxide-silica gel composite: a matrix effect. J Coord Chem 54:455-468

29. Solfa dos Santos V (2017) Voltammetric behavior of zinc hexacyanoferrate (III) nanoparticles and their application in the detection of N-acetylcysteine. Int J Electrochem Sci 7142-7153

30. Fenga PG, Stradiotto NR (2011) Study of zinc hexacyanoferratemodified platinum electrodes using electrochemical quartz crystal microbalance. J Solid State Electrochem 15:1279-1286

31. Fenga PG, Stradiotto NR, Pividori MI (2010) Preparation and characterization of graphite-epoxy composite modified with zinc hexacyanoferrate and their electrochemical behaviour in presence of substituted anilines. Electroanalysis 22:2979-2984

32. Eftekhari A (2002) Electrochemical behavior and electrocatalytic activity of a zinc hexacyanoferrate film directly modified electrode. J Electroanal Chem 537:59-66

33. Joseph J, Gomathi H, Rao GP (1997) Modification of carbon electrodes with zinc hexacyanoferrate. J Electroanal Chem 431:231-235

34. Kemmegne-Mbouguen JC, Angnes L, Mouafo-Tchinda E, Ngameni E (2015) Electrochemical determination of uric acid, dopamine and tryptophan at zinc hexacyanoferrate clay modified electrode. Electroanalysis 27:2387-2398
35. Mendoza-Huízar LH, Rios-Reyes CH, Gómez-Villegas MG (2009) Zinc electrodeposition from chloride solutions onto glassy carbon electrode. J Mex Chem Soc 53:243-247

36. Jassal V, Shanker U, Kaith BS, Shankar S (2015) Green synthesis of potassium zinc hexacyanoferrate nanocubes and their potential application in photocatalytic degradation of organic dyes. RSC Adv 5:26141-26149

37. Chen SM, Chan CM (2003) Preparation, characterization, and electrocatalytic properties of copper hexacyanoferrate film and bilayer film modified electrodes. J Electroanal Chem 543:161-173

38. Rutkowska IA, Stroka J, Galus Z (2008) Electrochemical properties of modified copper-thallium hexacyanoferrate electrode in the presence of different univalent cations. Electrochim Acta 53:3870-3878

39. Bárcena SM, Scholz F (2002) The thermodynamics of the insertion electrochemistry of solid metal hexacyanometallates. J Electroanal Chem 521:183-189

40. Scholz F, Dostal A (1996) The formal potentials of solid metal hexacyanometalates. Angew Chem, Int Ed Engl 34:2685-2687

41. Wessells CD, Peddada SV, McDowell MT et al (2011) The effect of insertion species on nanostructured open framework hexacyanoferrate battery electrodes. J Electrochem Soc 159:A98

42. Nightingale ER (1959) Phenomenological theory of ion solvation. Effective Radii of Hydrated Ions. J Phys Chem 63:1381-1387

Publisher's Note Springer Nature remains neutral with regard to jurisdictional claims in published maps and institutional affiliations. 